\title{
El firmamento como 'ser a desmano' y la caída: los paradigmas existenciales de la historia blumenberguiana de la astronomía ${ }^{1}$
}

\section{The sky as 'unavailable being' and the fall: existential paradigms of Hans Blumenberg's history of astronomy}

\author{
Alberto Fragio \\ (Eidgenössische Technische Hochschule Zürich. Chair for Science Studies)
}

Recibido: 04/10/2011

Aceptado: 19/04/2012

\section{Resumen}

Los estudios especializados sobre la obra de Hans Blumenberg [1920-1996] han prestado poca atención a su historia de la ciencia, en particular a su historia de la astronomía. A partir de 1955 Blumenberg empezó a ocuparse de la astronomía copernicana, y publicó diversos artículos relacionados con esta temática a finales de la década de los 50 y comienzos de los 60, luego recopilados en su Die kopernikanische Wende [1965]. Blumenberg preparó también estudios preliminares al Sidereus Nuncius de Galileo Galilei y al De coniecturis, de Cusa. Todo este trabajo fue culminado en su monumental Die Genesis der kopernikanischen Welt [1975], así como en el libro póstumo Die Vollzähligkeit der Sterne [1997]. El propósito de este artículo es tomar en consideración este ámbito específico de la obra de Blumenberg. Nos centraremos en la presencia de algunos motivos heideggerianos

\footnotetext{
${ }^{1}$ Este trabajo ha sido posible gracias a una beca postdoctoral del Gobierno suizo, disfrutada en la Eidgenössische Technische Hochschule Zürich durante el curso 2011/2012. Me gustaría expresar mi agradecimiento a Michael Hagner, a los miembros de la Chair for Science Studies (ETH-Zürich) y al Grupo permanente de Epistemología histórica e Historia de las emociones del Consejo Superior de Investigaciones Científicas (CSIC-Madrid). Esta investigación se ha beneficiado además del proyecto internacional "Historical Epistemology: Emotional Styles and Communities in the 19th and 20th Centuries", financiado por el Ministerio de Ciencia e Innovación de España (FFI2010-20 876) para el periodo 2011-2014; así como de una beca del Deutsches Literaturarchiv Marbach (Alemania), que me permitió consultar el Nachla $\beta$ de Hans Blumenberg en el verano de 2011.
} 
en la historia blumenberguiana de la astronomía. Defenderemos que en ella cabe identificar una metafísica de la existencia en sentido heideggeriano, en tanto paradigmas existenciales astronómicos.

Palabras clave: Sorge, curiosidad, contemplator caeli, metáforas de la indisponibilidad.

\section{Abstract}

A main area of Hans Blumenberg's works, the history of science, has received little attention, in particular Blumenberg's history of astronomy. Since 1955 Blumenberg [1920-1996] had undertaken a research on Copernican astronomy, and published many papers during the 50's and 60's, later put together in Die kopernikanische Wende [1965]. Blumenberg had also prepared preliminary studies on Galileo Galilei's Sidereus Nuncius and Cusa's De coniecturis. All this work will culminate in Blumenberg's monumental Die Genesis der kopernikanischen Welt [1975] and his posthumous book Die Vollzähligkeit der Sterne [1997]. The aim of this paper is to undertake a review on this neglected area of Blumenberg's works. We will focus on the Heideggerian background in Blumenberg's history of astronomy. Our thesis is that in Blumenberg's history of astronomy we can find a metaphysics of existence in a Heideggerian way, as astronomical existential paradigms.

Keywords: Sorge, curiosity, contemplator caeli, metaphors of unavailability.

La forma de ser de estos entes es el "ser a la mano". Mas no debe comprenderse en el sentido de un mero "carácter de apercepción", como si a los "entes" que hacen frente inmediatamente se les imbuyesen "aspectos", como si a una materia cósmica en si "ante los ojos" se la "colorease subjetivamente" de este modo inmediatamente. [...] Pero el "andar" "curándose de" no tropieza sólo con lo inempleable dentro de lo en cada caso ya "a la mano"; encuentra también aquello que falta, aquello que no sólo no es "manejable", sino que ni siquiera "está a mano". Un echar de menos en esta forma, un encontrarse ante algo "no a la mano", descubre de nuevo lo "a la mano" en un cierto "ser sólo ante los ojos". En el notar que algo "no es a la mano" se presenta lo "a la mano" en el modo de la "impertinencia".

(Martin Heidegger, Sein und Zeit, §§ 15-16) 
-Su capacidad de admiración hacia la naturaleza es limitada, querido señor Blumenberg. Por lo menos para la terrestre. Las estrellas permanecen intactas...

-... la astronomía ha recorrido el camino de la decepción mucho antes y mucho más lejos que la fisiología. [...] Usted sabe tan bien como yo, señor Ritter, que admiro al hombre. Lo único que no admiro es su propensión a los transtornos.

(Conversación entre Joachim Ritter y Hans Blumenberg,

"Kreislauf", Begriffe in Geschichten).

\section{La indisponibilidad del firmamento: el cielo estrellado como paradigmática existencial}

Que vivimos en la Tierra pero vemos las estrellas, es una condición existencial común tanto a la astronomía como a la antropogénesis $(G k W 11,3){ }^{2} \mathrm{El}$ primer antropoide hubo de poner en suspenso la inquietud por lo cercano, garantía de su supervivencia, para poder redirigirla al inmenso cielo estrellado que se extendía por encima de su cabeza, abandonando de este modo y por un instante "el camino usual", sustrayéndose así "al contacto provechoso con el mundo" (LdT 147, 193). Al levantar su mirada a lo más alto y lejano había de ocultar, siquiera por un momento, lo más bajo y cercano $(S d P 14,10)$. La condición para observar el cielo, el comienzo de la astronomía, pasaba entonces por desatender el suelo firme que se extiende bajo los pies: un peligroso desinterés hacia aquello próximo e inmediato que hace las veces de soporte $(L d T 66,88)$. Esta nueva "cura del ver" ["die Sorge des Sehens"] (LdT 152,198) -en la expresión de Heidegger- involucraba una paradoja cargada de significado antropológico: convertía "lo lejano, aquello que sólo puede percibirse, en algo cercano al hombre" (LdT 152, 198).

Esta Sorge por los astros estaba llamada a propiciar una inmoderada inquietud respecto a lo distante e inútil, la preocupación insidiosa por aquello de allá arriba brillante "que no está al alcance de la mano por antonomasia" (LdT 152, 198), y que impide, a su vez, la "permanencia en lo próximo" $(\operatorname{LdT} 153,199)$. El curarse de

\footnotetext{
2 Adopto las siglas de César G. Cantón, La metaforología de Blumenberg como destino de la analítica existencial, Universidad Complutense de Madrid, 2004, pp. 378-80. Modo de citación con siglas: entre paréntesis y en cursiva se indica la abreviatura acompañada por la página del original alemán. Tras una coma le sigue en redonda la página correspondiente de la traducción española, si la hay, o de alguna otra traducción en un idioma diferente al español. Por ejemplo: $(H 785,644)$. Cuando no se ha tenido acceso al texto original, tan sólo se indica la paginación en letra redonda de la traducción utilizada, antecedida por una coma. Por ejemplo: $(B i G, 129)$. En el caso contrario, cuando sólo se disponía del texto original, se ha indicado la página en cursiva después de la abreviatura, ambos en cursiva y sin coma. Por ejemplo: (Lt 120). En la relación bibliográfica final figuran las traducciones empleadas.
} 
la lejanía, fundamento antropológico de la ciencia astronómica, invitaba, por añadidura, a la pasividad, al "no-tener-que-intervenir como un mero ser-entretenido por el mundo" (LdT 153, 199).

El cielo estrellado, desde la perspectiva del paradigma existencial-antropogenético, viene caracterizado, en consecuencia, por permanecer inaccesible e inalcanzable (GkW 25 y 120,17 y 99; $S d P 16$ y $38-9,13$ y 47-8). Las estrellas resultan "entidades intangibles, impalpables, meramente ópticas, que se manifiestan al ojo sólo como luz, como seres puramente espirituales, sobrehumanos, divinos, o más bien como entes de la fantasía". ${ }^{3}$ Por ello, los cielos estrellados bajo los cuales se desarrollaba la antropogénesis estaban cargados de ambigüedad (GkW 11-5, 3-7), en la medida en que su carácter indisponible preservaba la duda sobre si allí era albergado lo esencial oculto que aún no es $(S d P 63,88)$, o bien la desconcertante cifra de lo eternamente irrelevante para el hombre $(S d P 54,73)$. En cualquier caso, cabía concluir que no todo puede convertirse en objeto de experiencia, y que precisamente ahí, en lo alto, estaba la escandalosa esfera de lo indeterminado ( $S d P$ 53, 71; GkW $28,19)$, como el difuso horizonte capaz de ampliar "la lejanía hasta lo aún no explorado en absoluto" (LdT 153, 199), es decir, hasta ese abrumador e insondable resto de lo inalcanzable en el que se abre lo otro enorme, desconocido en su raíz e irremediablemente a desmano.

Desde el punto de vista del mundo de la vida, el firmamento, en suma, es aquello que en su radical indisponibilidad no se deja subyugar por el hombre (GkW 102, 84), pues establece el límite natural e insuperable de la acción humana, una incómoda presencia acechante apenas sí conceptuable. El hombre no puede intervenir sobre el cielo estrellado ni está en condiciones de dar cuenta de él: "la realidad del universo es experimentada como una resistencia a los conceptos" $(G k W 76,61)$. Es más: "la única razón por la que la totalidad de la naturaleza no puede ser conceptualizada consiste en que ésta no se originó en conceptos" (GkW 76, 62). Es decir, lo genuinamente visible y notable en las estepas de la antropogénesis era la llamativa inhumanidad del firmamento, la insalvable distancia ontológica entre lo que es y su representación; entre la inmensidad del cielo estrellado y su modesta percepción desde la fangosa superficie terrestre: "la insuficiencia de la presencia intuitiva del universo, en cualquier momento dado, ofrece la ocasión al concepto para la construccion de la historia del universo como la dimensión en la que todo resulta concebible" $(G k W 76,62)$. El concepto fracasa estrepitosamente ante la magnitud inabordable del firmamento, en la pluralidad delirante de sus sucesivas imágenes.

Pero por más que la realidad no sea originariamente conceptual, no cabe por ello disminuir la radicalidad inherente a la demanda de una justificación del universo, de una cosmodicea ( $G k W 103$ y ss., 85 y ss). El "paradigma del cielo estrella-

${ }^{3}$ Ludwig Feuerbach, Die Unsterblichkeitsfrage vom Standpunkt der Anthropologie [1846], in Sämtl. Werke, vol. 1, p. 125, citado por Blumenberg (SdP 53-4, 72). 
do" ["Paradigma des gestirnten Himmels"] $(G k W 105,86)$ muestra así su consistencia en tanto remanente ineliminable, como aquello que subsistió "tras el fracaso (y en la conciencia del fracaso) de los esfuerzos soportados durante siglos por justificar a Dios y su trabajo [...], en el abismo de la pregunta no contestada ni contestable por la razón del ser" (GkW 105, 86).

A nuestro juicio, la historia blumenberguiana de la astronomía no será sino la asunción de este enclave existencial-antropológico; del conjunto de esperanzas, miedos y expectativas que el cielo estrellado ha despertado en el mundo de la vida. Recoge su no menos increíble cumplimiento, ese inesperado "y aún" ["Und doch"] $(G k W 135,112)$ propio de la ganancia de realidad tras el desplazamiento histórico de la experiencia astronómica. En este sentido, la historia de la astronomía y sus ambivalentes conquistas, constituyen para Blumenberg un modelo privilegiado de conocimiento -quizá junto con la biología (dem 19; GkW 128, 105) -4 puesto que ilustran ejemplarmente la facticidad de la existencia humana, la condición marginal del hombre en el universo. La astronomía, a diferencia de otras disciplinas científicas, despeja el camino para una peculiar conciencia de sí del hombre, más apegada a la tierra y menos seducida por los fulgores de un orden intelectual que en el fondo no le pertenecen. ${ }^{5}$ La desmesura de la realidad, su absolutismo, se muestra con mayor claridad en la brutal desproporción entre el limitado espacio que pisamos y el inmenso cielo estrellado suspendido sobre nosotros. ${ }^{6}$

\footnotetext{
${ }^{4}$ Nos referimos, por supuesto, a Darwin. Quien con más intensidad ha pensado el desarrollo de la vida en la Tierra, tuvo también que pensar la muerte. La teoría de la evolución de las especies es sin duda una descomunal necrología. Darwin pronto se dio cuenta de que explicar la vida exigía estar constantemente hablando de la muerte, de la desaparición y la pérdida, de la dramática lucha por la existencia y de su desenlace más común y fatídico. Quizá ninguna otra metáfora ilustra mejor esta circunstancia como la metáfora del árbol de la vida. Darwin hizo uso de ella para representar la evolución de las especies por medio del mecanismo de la selección natural. Su tronco eran las primeras formas de vida que habían habitado el planeta, a partir de las cuales se produjo la diversificación posterior, las diferentes ramas que crecen hasta penetrar en nuestros días: el orden biológico actual. Pero su árbol de la vida era, después de todo, un árbol del tiempo, un árbol de la muerte. Las especies vivientes que pueblan la Tierra son como las pequeñas "yemas" que reverdecen en una rama muerta, constituida por la suma abrumadora de todos los organismos ya extinguidos. Su árbol de las especies no dejaba de ser un enorme cadáver, aún mantenido en pie, del que brotaba la vida en proporción inmensamente más pequeña que el cuerpo muerto que la alojaba. Véase Charles Darwin, Teoría de la evolución, Ediciones Altaya, Barcelona, 1999, pp. 72-4.

5 Recordemos lo que Blumenberg decía en Die ontologische Distanz a propósito de la ciencia "Die Welt der Wissenschaft ist nicht die Welt, in der wir "leben"': "el mundo de la ciencia no es el mundo en el que vivimos" (oD 19).

6 El propio Odo Marquard, quien popularizó la interpretación de la obra de Blumenberg desde el "absolutismo de la realidad", sugería en su contribución al volumen homenaje preparado con motivo del 70 cumpleaños de Blumenberg, que mirando o lo lejos nos libramos del absolutismo de lo que está bajo nuestros pies. Véase Odo Marquard, "Lebenszeit und Lesezeit. Bemerkungen zum Cuvre von Hans Blumenberg" en Michael Krüger (ed.), Akzente. Hans Blumenberg zum 70. Geburtstag, 37 Jahrgang, Heft 3, Juni 1990, p. 269.
} 


\section{Los dos máximos paradigmas existenciales astronómicos}

Al interior de la paradigmática existencial astronómica podemos distinguir dos paradigmas históricos prevalentes, que definen sendos casos límite de un espectro mayor: el paradigma astrológico y el paradigma de la indiferencia del universo, ambos de claro alcance metaforológico y antropológico. El primero de ellos ofrece la imagen de un cosmos servicial intrínsecamente significativo, que no cesa de enviar señales al hombre y que está representado por la astrología. En la visión astrológica del mundo, los movimientos celestes "asumen claramente el valor de un signo" ["der Himmel konnte noch einmal im Zeichen deutlich werden"] (SdP 38, 48), prefiguran la buena o mala fortuna reservada a los hombres, de tal modo, que para tomar posesión de las condiciones determinantes de su existencia, deben descifrar el contenido existencial concreto que la trayectoria de los astros esconde, para poder así actuar en consecuencia: "la astrología une al hombre con el universo, ahora depositario de la suma de señales que pueda precisar, convirtiéndo al ser humano en el punto de referencia de cualquier proceso fisico" $(\mathrm{GkW} 75,60)$. En la medida en que "representa las necesidades insitas e inextirpables en el sustrato del hombre" (SdP 32-3, 40), la astrología es un reflejo del ancestral anhelo antropológico de que el conjunto de la existencia, y en especial la vida de los individuos, atienda a un orden comprensible y propicio. A saber: que el destino humano esté sujeto a razones y no se muestre contingente o arbitrario en sus cadenas causales. Se espera de la astrología, entonces, que sea capaz de dar respuesta a cualquier posible pregunta $(S d P 33,41)$, por más bizarra que ésta pueda llegar a ser, y pese al notable inconveniente de que plantear muchas preguntas pueda comportar quizá recibir demasiadas respuestas ( $L d T$ 64-5, 86-7). El paradigma existencial astrológico se basa, por tanto, en un cosmos antropomórfico que vela constantemente por el hombre, afín a sus esperanzas más íntimas de realización y congruente con la exigua duración de la vida humana ( $L W$ 99-129, 89-114); un cosmos en el que todo permanece disponible a voluntad, perfectamente a la mano, y sometido -en la acertada expresión de Nietzsche- "a la norma tiránica del espíritu" ["Tyrannenherrschaft des Geistes"] (GkW 127, 104; GdT 104). La astrología no es, en consecuencia, "una forma degenerada de la astronomía" sino un "modelo para el grado de participación entre el hombre y el mundo" (GkW 123, 102), que llevado a su expresión más acabada, hace coincidir el curso de los astros con el de la historia $(S d P 50,67)$.

El paradigma existencial de la indiferencia del universo, por el contrario, supone una inversión exacta del paradigma astrológico: el cielo estrellado no participa en modo alguno de la felicidad del hombre, no conspira en su provecho ni le manifiesta respuestas oportunas que sólo él ha de oir con privilegiada satisfacción ( $G k W$ 30-1, 21). Queda por completo neutralizado "el potencial simbólico de los astros" ["Neutralisierung der Anfälligkeit für Zeichen"] (SdP 39, 49), cuyo movimiento 
aparente -ya estrictamente mecánico- ha perdido cualquier significación para la marcha de los asuntos humanos. Con absurda tenacidad, y tal como testimonia la vacua e innegociable repetición de sus órbitas, los cuerpos celestes se revelan ajenos y refractarios a los intereses particulares del hombre. A la manera del astrologue cocu de Thomas Moro, Geoffrey Chaucer o Samuel Richardson, en este paradigma el observador con vocación astrológica no es capaz de descubrir en las estrellas "su propio infortunio matrimonial" (LdT 114-5, 150; SdP 45-50, 58-9). En la superficie del firmamento se constata más bien la flagrante "indiferencia de la naturaleza respecto al hombre y su destino" (SdP 45-50, 59). Es, en suma, la imagen de un universo "frío, insensible, malignamente brillante e impasible de un modo despreciativo a la suerte del hombre" (SdP 45-50, 59-60). Los cuerpos celestes que componen este universo son despojados por completo de su carácter empático, pasan a convertirse en gélidos y relucientes fantasmas que atraviesan con sigilo el cielo nocturno de la Tierra $(G k W$ 84, 68).

La base histórica de este último paradigma existencial reside en lo que Blumenberg denomina "la reforma copernicana" ["die kopernikanische Reform der Astronomie"] (GkW 155, 128). Esta inversión astronómica será dramáticamente puesta de relieve en la concepción del mundo de Copérnico, que por otra parte inaugura la Modernidad. Si bien implica una renovación tardía del cosmos griego antiguo - esto es, de la comprensión del universo como una realidad ordenada, segura y a la altura de las posibilidades epistemológicas del hombre- este nuevo cosmos habrá dejado de inspirar confianza, siendo más bien objeto de toda clase de suspicacias ante el escándalo de su inclemente mutismo $(G k W 83-4,68)$. Por más que el copernicanismo hubiese conservado importantes reminiscencias de la antigua teleología antropocéntrica griega y romana, su heliocentrismo estará lleno de ambigüedades. No es la menor de ellas que el ser humano esté relegado a una posición excéntrica en la todavía finita machina mundi ( $G k W$ 204-5, 172-3). El sistema copernicano no era capaz de eliminar los "temores apocalipticos" ["apokalyptische Ängste"] $(G k W 314,267)$, como por ejemplo aquél que preveía la destrucción del globo terrestre por efecto del movimiento rotacional de la Tierra: todo su contenido habría de salir disparado al espacio exterior ( $G k W$ 313-6, 266-9). Si bien la maniobra astronómica copernicana había "salvado" el cosmos griego de su completa disolución, este cosmos redivivo dejaba de enviar benevolentes "señales al hombre para su autocomprensión" (GkW 75, 60). En su lugar, instalaba un vertiginoso impetus nihilista $(G k W 30,21)$, acrecentado por la insoportable devaluación del hombre en un mundo cada vez más periférico. Nietzsche lo formulará con gran acierto: "El hombre parece hallarse desde Copérnico en una rampa inclinada: cada vez rueda más deprisa alejándose del centro, ¿hacia dónde? ¿hacia la nada? ¿hacia el punzante sentido de su nada?".7

7 Friedrich Nietzsche, Sämtliche Werke, vol. 5, Munich, 1980, p. 404, citado por Blumenberg en (GkW 126-7, 104-5). Este mismo pasaje lo había citado Blumenberg en su "Introducción" a Nicolaus von 
Pese a que en esta nueva configuración cosmológica el universo siga siendo asequible a la razón humana, habrá dejado de velar celosamente por el bienestar del hombre (GkW 130-1, 107-8), pues una parte inmensa, si no toda, "nada tiene que ver con la felicidad humana" (GkW 139, 115), más aún cuando se empieza a sospechar que quizá, y despues de todo, ha venido siendo muy menguada "la magnitud del universo empiricamente accesible" (GkW 157, 130).

\section{La semántica antropológica del cosmos}

Lo que principalmente parece interesarle a Blumenberg en la historia de la astronomía no es tanto la progresiva constitución científica de esta disciplina como su gran aportación a la comprensión que el hombre ha tenido de sí mismo y de la realidad. Esto es, "la formación del trasfondo cósmico de la historia de la conciencia humana" ["die Formierung des kosmischen Hintergrundes der menschlichen Bewußtseinsgeschichte"] (GkW 15, 6). De este modo, los análisis histórico-filosóficos de Blumenberg se concentran en la transformación epocal de las relaciones entre mundo y conciencia a través de los sucesivos logros astronómicos, desde el geocentrismo hasta el heliocentrismo y la astronomía postcopernicana. Podemos decir en este sentido que la historia blumenberguiana de la astronomía es una "semántica antropológica de la cosmología" ["die anthropologische Semantik der Kosmologie"] (GkW 27, 18), en la expresión del propio Blumenberg. La historia de las comprensiones del cielo estrellado correspondería entonces con la historia de las comprensiones que el hombre ha tenido de sí ( $G k W 127,104)$, cuyo punto culminante viene dado, precisamente, por el paradigma existencial de la indiferencia. En un universo frío, hostil y en creciente expansión, la cosmología no podía sino emplazar al observador de los astros hacia sí mismo, al saber antropológico. De tal manera que la "función indicativa de la cosmología" $(G k W 565,486)$ se traduce después de todo en acción humana, en la tarea de construir un mundo a la medida del hombre y como ejercicio de su propia libertad.

Este proceso será para Blumenberg iniciado con la astronomía moderna, ligada, como decimos, a la autoconstitución autónoma del hombre. La insoportable acumulación de desilusiones derivadas de la exploración del universo, en especial la posición periférica de la Tierra en el orbe celeste, empujó al hombre moderno a una huída hacia lo conocido, al ámbito restringido de lo que le era más cercano y fami-

Cues, Die Kunst der Vermutung. Auswahl aus den Schriften, (edición de Hans Blumenberg), Bremen, Schünemann, 1957, p. 8. La desazón provocada por los nuevos hallazgos puede ser resumida también con las inspiradas palabras de Erwin Panofsky: "el hombre se encontró enfrentado con el infinito como cualidad del universo, en vez de ser una prerrogativa de Dios". En E. Panofsky, "El padre tiempo", en Estudios sobre iconología [1962], trad. esp. de Bernardo Fernández, Alianza Universidad, Madrid, 2004, pp. 115-6. 
liar: él mismo y el suelo bajo sus pies, que pasa ahora a convertirse en lo más importante en absoluto, y en objeto de autoafirmación. Tras la pérdida del "significado antropológico del mundo" (GkW 75,61) y el descubrimiento de su inesperada excentricidad, el hombre moderno ha tenido que remitificar la Tierra y a sí mismo, replegándose en una autopercepción de ser preeminente, que se eleva por encima del conjunto de lo existente ( $G k W 29-30$ y 107, 20 y 88). La vía moderna de mitigar el impacto producido por la decepción copernicana consistió, por tanto, en rehabilitar formas antropocéntricas compensatorias $(G k W 98,80)$, apelando a la universalidad de la razón y a la independencia de sus logros, posibilitando, en suma, una nueva autocomprensión del hombre y de su realidad más inmediata $(G k W 91-2,75)$. Frente a las dificultades surgidas a la hora de justificar la contingencia de lo dado, el hombre moderno encontró en la autointensificación de su propio ser y de los resultados de su acción sobre el mundo, un conveniente paliativo a la nada que le mostraba el universo, esto es, en el "absolutismo antropológico" ["anthropologischen Absolutismus"] (GkW 106, 87).

En este sentido, creemos ver en la historia blumenberguiana de la astronomía una forma de continuar con la historia de la ontología por otros medios, especialmente en las sucesivas "legitimaciones de la comprensión de sí del hombre con la ayuda de un esquema físico" (GkW 108, 89), y en particular en las consecuencias metafísicas y antropológicas derivadas de cada imagen del mundo ( $G k W$ 307-8, 262). Un cosmos indestructible, fiable y ordenado por leyes inalterables no suscitará el mismo concepto de realidad que un universo proclive al colapso escatológico o a la multiplicación de nuevos y perturbadores cuerpos celestes como estrellas, cometas o planetas $(G k W 45,33)$. En el derrumbe del "sistema dogmático más cerrado de la explicación del mundo" (GkW 198, 167), el sistema geocéntrico, se ubicará la gran transformación metafísica que hizo posible el copernicanismo: "desde este punto de vista, la 'prehistoria'de la reforma copernica no se presenta como la consolidación y convergencia gradual de un conjunto de elementos que culminan en una necesidad histórica inapelable" (GkW 198, 167), sino como las condiciones efectivas que la hicieron posible. Para Blumenberg, "el emocionante problema histórico del cambio de época no es precisamente la explicación del hecho de los logros copernicanos, o incluso de la afirmación de su necesidad, sino el de encontrar las bases de su mera posibilidad" $(G k W 198,167)$. Y esta posibilidad no puede ser otra que la del cambio radical del concepto de realidad subyacente y de su específico acceso epistemológico. Sin la crisis de la Escolástica, que sancionaba la filosofía natural con la que Copérnico abordó su reforma astronómica, y sin la tradición humanista, que renovaba un antropocentrismo no teleológico dignificador de la razón humana, habría sido inviable, a juicio de Blumenberg, una modificación tan profunda de la imagen geocéntrica del mundo como la operada por el astrónomo polaco $(G k W 165,138)$ : "el cambio propiciado por Copérnico sobre la 
conciencia histórica de la humanidad habría sido en sí mismo inconcebible, en su dimensión radical, sin su oposición al trasfondo y consecuencias de la historia anterior de la relación del hombre con su entorno cósmico, una historia nunca antes interrumpida y desprovista de un comienzo designable" $(G k W 13-4,5)$.

\section{El contemplator caeli}

Un individuo mirando el cielo estrellado queda como la figura persistente de los trabajos de Blumenberg sobre historia de la astronomía ( $C C$; $G k W$; $S d P ; L d T$; $S Z$ ). Este contemplator caeli define un tipo humano que, poseído por una acuciante curiosidad, se adentra insensatamente en lo profundo de la noche con el propósito de observar el firmamento centelleante, suscitando con su extravagante conducta la suspicacia de sus contemporáneos. El astrónomo se vincula así con el theoros, el improductivo "espectador del mundo" ( $L d T$ 1, 9; SZ), desembarazado de cualquier preocupación común e inclinado a abandonarse a la inútil persecución de los astros. Presa de una Sorge ilimitada por el cielo estrellado, concentra ardorosamente sus energías en toda aquella brillante suspensión, pasando por alto los intereses humanos diurnos, asumiendo toda clase de riesgos y peligros innecesarios. Su Sorge por los astros le lleva a una continúa exposición de sí mismo $(G k W 121,100)$, hasta el extremo de caer "víctima de su propio impulso" (SdP 15-6, 12). La "rareza del espectador nocturno del mundo" (LdT 1,9-10) despunta así sobre las nudas y bien conocidas condiciones existenciales que soportan y hacen posible la teoría. Ésta, como el amor, genera formas de comportamiento que no son fácilmente disimulables $(L d T 2,11)$, y pese a que su fundamento no sea visible en sí mismo, sí lo son, en cambio, las extrañas y llamativas conductas que provoca, que con facilidad despiertan el escándalo de quienes han de presenciarlas: "el comportamiento teórico consiste en acciones que están sujetas a reglas intencionales y que conducen a complejos de enunciados en conexiones reguladas, pero esas acciones sólo por su lado externo son interpretables como 'ejecuciones' de algo. A alguien no iniciado en su intencionalidad, que ni siquiera sea capaz de suponer por su modalidad que pertenecen a la 'teoría', tienen que resultarle enigmáticas y pueden parecerle chocantes $y$ hasta ridiculas" (LdT 9, 15).

La observación de los astros y sus correspondientes "esfuerzos teóricos nocturnos" (SdP 56, 76) se convierten de este modo en fuente inagotable de "tensiones y malentendidos entre el mundo de la vida y la teoría" (LdT 11, 18), pues apenas se alcanza a comprender desde fuera qué es lo que puede haber en esos enigmáticos objetos que los hace capaces de absorber una vida entera de trabajo ( $\operatorname{LdT} 10,17)$. Quizá nadie percibe ya rareza alguna en la actividad del astrónomo contemporáneo, pues sus imponentes y costosísimos instrumentos de observación le eximen de tener 
que deambular a tientas en la espesa oscuridad mientras los demás duermen con merecida placidez. Sólo tardíamente, sin embargo, ha sido posible una conciliación semejante con el "mundo terrestre de la vida" ( $G k W$ 499, 428), una vez fue incorporado "el ascetismo de los códigos profesionales y se cumplió con lo que puede denominarse "valores para la vida"” $(G k W 23,14)$. Detrás queda la largísima y accidentada singladura del contemplator caeli, su insidiosa confrontación con el "mundo de la vida", imprescindible para remontar la incongruencia entre la diáfana y consabida intuición mundana y las difíciles sutilezas de la racionalidad astronómica $(G k W 52,40)$.

Las proezas de la astronomía han requerido del progresivo abandono de la percepción común de los fenómenos como "base inicial y norma para un cumplido conocimiento de la naturaleza" (GkW 470, 402), desvirtuando así, tal como Husserl indicó, "el 'significado fundamental' de cualquier proceso teórico en la esfera intuitiva del "mundo de la vida" (GkW 470,402). Todo lo que se ofrece por medio de la percepción ha de ser experimentado -y asimismo ha de ser experimentableen el "mundo cotidiano de la vida" (GkW 470, 402). Pero la astronomía no ha cesado de agrandar, por el contrario, el "hiato entre teoría y vida" $(S d P 17,15)$, haciendo impracticable la "reducción de la cosmología al estado de inocencia de un mundo de la vida preteórico" $(G k W 78,63)$. Con ello ha impedido la pacificación de su perenne conflicto con la cotidianeidad diurna. La astronomía se vió entonces incapaz de salvar la distancia respecto a sus motivaciones originales, que se ubican precisamente en ese mundo de la vida que ha de denostar para poder iniciar alguna vez su andadura: "la renuncia a la intuición es una precondición de la ciencia [...]; la pérdida de la intuición es una consecuencia necesaria de cualquier teoría que se sistematiza a sí misma, esto es, que consolida y organiza sus resultados de modo tal que, en virtud de su orden heterogéneo, toma esos resultados como la forma de acceder a los fenómenos originales y finalmente adquiere el puesto de ellos. Los resultados de la ciencia tienen, en un grado siempre creciente, la peculiaridad de que contienen el conocimiento como un estado final que ya no puede ser relacionado con ninguna clase de objeto previo familiar" $(G k W 61,47) .{ }^{8}$ El saber astronómico sólo retorna al mundo de la vida cuando ofrece respuestas a preguntas anteriormente planteadas en él $(G k W 61,47)$, en tanto se muestra, por ejemplo, en condiciones de augurar abundantes cosechas, predecir eclipses o eliminar los temores que el capricho de los astros pueda despertar en los habitantes de la Tierra. Pero el mundo de la vida reclama su valor fundante, sobre todo en el drástico recordatorio de la importancia de la cotidianidad (SdP 20-1, 20-1), poniendo el énfasis no sólo en la gravosa disparidad entre los requerimientos inasumibles del impulso teórico y

8 Conviene recordar que esta misma cuestión fue ya anticipada en el trabajo de habilitación de Blumenberg, en su revisión crítica de la fenomenología husserliana ( $o D$, Erster Teil §§ 1-6 y Dritter Teil $\S \S 4-8)$. 
la finitud de la vida $(S d P 36-7,44)$, sino llamando la atención sobre la "diferencia entre la exigencia de la teoría y la moderación de la práctica" $(S d P 60,84)$.

\section{El contemplator caeli en perspectiva histórica}

Merece la pena que nos detengamos brevemente en señalar algunos hitos y rasgos reseñables del contemplator caeli puestos de relieve en la historia blumenberguiana de la astronomía. Destaca en primer lugar la tradición griega antigua, y de manera especial, la estoica. Para el observador heleno queda excluido de la realidad "todo aquello que no es directamente accesible a la facultad humana" (GkW 731, 629). Esta asunción se basa en lo que Blumenberg denomina el "postulado de visibilidad" (GkW 731, 629), de acuerdo con el cual el cosmos está esencialmente coordinado con el hombre, de modo que no cabe esperar incongruencia alguna entre su constitución física y la arquitectura general del mundo: "el postulado de visibilidad se sigue de la construcción simétrica del universo geocéntrico y la posición central del hombre en él $(G k W 731,629)$. En este esquema, el firmamento está configurado por estrellas fijas equidistantes de la Tierra, y se puede descartar que existan otras estrellas ocultas que escapen a la capacidad de percepción humana: "si cada estrella singular puede ser percibida, entonces han de ser todas perceptibles" (GkW $731,629)$. En principio no parecen necesarios medios adicionales destinados a optimizar la visión ofrecida por el ojo desnudo, pues el cielo estrellado se muestra con perfección suficiente como para que sea asequible tanto a las posibilidades cognoscitivas del hombre como a sus competencias intelectuales. Aún es más: la propia magnificencia del cosmos requiere de la presencia del spectator mundi, pues de otra manera su grandeza sería vana: "una belleza tan evidente no puede ser concebida sin alguien que se deleite con ella" (GkW 26,17).

Es ésta la versión ejemplar del contemplator caeli que, como el Anaxágoras de Diógenes Laercio, encuentra la razón última de su existencia en la franca posibilidad de "observar el Sol, la Luna y los cielos" (GkW 22, 13). Obtiene, por ende, mayor placer en la contemplación de la naturaleza que en los asuntos públicos de la polis $(G k W 19,11)$. Así las cosas, el espectador griego del cielo creerá ver en el firmamento de las estrellas fijas el contacto con una realidad superior, "con una realidad más pura, con la parte de la naturaleza más cercana al pensamiento" (LdT $121,159)$. Es por ello que la perfecta simetría entre el cosmos y su representación dejará paso ocasionalmente a "un ideal de captación de la realidad en la dimensión de lo inaccesible y, por tanto, de la 'pura' admiración" (LdT 121, 159), haciendo del firmamento un objeto ejemplar cada vez más inalcanzable $(S d P 44,56)$, como en los casos de Aristóteles o Ptolomeo (GkW 250, 211). 
El antiguo espectador griego de un cosmos geocéntrico y tendencialmente antropocéntrico, será reemplazado por el observador gnóstico del mundo, para quien el espectáculo del cielo estrellado resulta, después de todo, engañoso y decepcionante $(G k W 32,22)$. El grandilocuente oropel celeste escamotea la verdadera posición del hombre en el mundo, que no es sino la de alguien que, en la miseria de su prolongado destierro, ha llegado incluso a olvidar su propia procedencia. El deslumbrante esplendor del firmamento hace creer al ingenuo observador nocturno que está en el sitio justo en el momento preciso, que todo aquello está dispuesto para complacerle y dignificarle, mientras que la triste realidad es que forma parte de una nefanda artimaña ejecutada por poderes ocultos y malignos, concebida para alejar al hombre de Dios y perpetuar su sometimiento en la Tierra. El espectador gnóstico asiste con incredulidad a la visión de un cosmos demonizado, intrínsecamente malo, que intenta seducirle con su equívoca apariencia de familiaridad ( $G k W 35-6$, $25)$. En este sentido, el contemplator caeli gnóstico sería una prefiguración del creyente cristiano y de su escepticismo respecto a los cielos, pues queda emplazado a ignorar los ídolos celestes para atisbar al Creador que tras ellos se esconde ( $S d P 26$, 30). La aparente centralidad del hombre le hace olvidar que él propiamente no pertenece al cosmos y que su salvación pasa, en efecto, por la destrucción del mundo ( $G k W$ 317-8, 270). Habría, en consecuencia, una anticipación de la escatología cristiana en el gnosticismo, en la medida en que la salvación personal está negativamente condicionada a la estabilidad del cosmos (GkW 35-6, 25): a su inminente ruina le sigue el esplendor auténtico del paraíso.

El observador cristiano oscila, sin embargo, entre "los valores iniciales extremos del estoicismo y los del gnosticismo" (GkW 32, 22), de modo tal que si bien ha de mostrarse cauto en su admiración hacia el firmamento, no por ello deja de considerarse el centro de la creación. Se resiste a aceptar que su punto de vista y lo que en él se le ofrece sea abiertamente fútil y contingente. Tiene entonces que "mudarse sistemáticamente al punto de observación a él asignado: en el centro de los movimientos" ( $S d P 25,28)$, donde puede orientarse en la vía correcta que lo lleva hacia la transcendencia. Pero además "de la hostilidad hacia el cosmos y su seguridad" (GkW 317, 270), el observador cristiano aprendió de la gnosis a moderar su avidez por saber, a encauzar su curiosidad astronómica, preservando, no obstante, la teleología antropocéntrica $(G k W 39,28 ; S d P$ 34-5, 43). El cielo es ciertamente el lugar de "los asuntos divinos" (GkW 40,29), pero el hombre no puede aspirar a inmiscuirse en ellos a su antojo. El espectador cristiano tendrá, por tanto, que "elegir entre dos posibles y opuestas direcciones de la mirada" (SdP 47, 62), en su confianza "en la totalidad alcanzable del conocimiento" ["das erreichbare Ganze der Erkenntnis"] $(L d T 68,91)$ o en que "el secreto natural y su respectiva inaccesibilidad testimonian la voluntad divina" (LdT 68, 91); entre un Dios que tiene obligaciones para con el hombre y debe garantizar las condiciones de accesibilidad cog- 
noscitiva del mundo ( $G k W 234-5,198)$, o bien un Dios inescrutable tanto en sus designios como en la intención y naturaleza última de su creación. No será fácil decidir, en suma, si "las órbitas descritas en el cielo son el resultado de una voluntad inaccesible" (SdP 30,36), o más bien la prueba fehaciente de la omnipotencia divina. La figura del astrónomo cristiano se inscribe de este modo en el "desencuentro entre el elemento filosófico-antiguo y el bíblico-teológico" (SdP 29-30, 35). La astronomía de la época "cree poder establecer con claridad la fiabilidad del ordenamiento y de las leyes del cosmos, pero no puede afirmarla por encima de cualquier reserva 'superior' de intervención y de mediación, si es que desea acreditar la indefectibilidad de sus afirmaciones" (SdP 29-30, 35). La astronomía medieval se debate así entre lo vinculante de sus resultados y la insistente apelación a una transcendencia. La crisis de época de la Edad Media, sobre todo con el Nominalismo, traerá consigo la supresión de los últimos residuos de teleología cósmica antropocéntrica, y con ello echará a perder la posibilidad de un conocimiento cumplido y garantizado del universo ( $G k W$ 236-9, 200-2).

No obstante, durante el Renacimiento se rehabilitará, como ya hemos anticipado, la idea antigua de la posición central del hombre en el cosmos $(G k W 48,36)$, pero sin el providencialismo propio de una antropología teleológica. La principal consecuencia de este punto de vista consiste en la dignificación y autonomía del hombre respecto al mundo, que ahora se empieza a revelar -de nuevo- a la altura de la razón humana: la posición central del hombre no es sino la prueba de la racionalidad del mundo $(G k W 565,486)$. Es este humanismo renacentista, así como la carga platónica que lleva asociada, el que estará a la base -en el planteamiento de Blumenberg- de la reforma astronómica copernicana y de su contemplator caeli heliocéntrico, en tanto sólo en esta tradición se podían asegurar los privilegios del hombre en relación con lo existente sin apelar a una cuestionable inocencia antropológica a la manera del naturalismo estoico ( $G k W 239$ y 580-1, 202 y 499; KuS 6180). Esta tradición permitía, asimismo, salvar el escollo del escepticismo epistemológico nominalista y de la tardía teología de la salvación $(G k W 240,203)$. Es decir, el humanismo y la herencia platónica característicos del Renacimiento, hacían posible un "antropocentrismo racional" ["rationale Anthropozentrik"] $(G k W 48,36)$, como es, entiende Blumenberg, el de Copérnico ( $k k W$ 204-13, 173-7). Que el mundo, después de todo, esté hecho para el hombre, garantiza su accesibilidad a la razón humana, pese a que no pueda asegurar, por otra parte, la continuidad de la vida en la Tierra $(G k W 237,200)$. Todo ello venía a parar en la preservación del antiguo postulado de visibilidad ( $G k W 737$ y ss., 635 y ss.), en la correspondencia perfecta entre lo que se ve en los cielos y lo que en ellos existe realmente, por más que el observador copernicano haya perdido ciertamente su quietud ["Am Ende des ruhenden Betrachters"] $(G k W$ 47, 35). 
Sin embargo, una configuración excéntrica como la propuesta por el heliocentrismo copernicano complicaba mucho, en última instancia, el mantenimiento del postulado de visibilidad, puesto que la perspectiva terrestre no podía sino convertir la percepción de los astros en una "convergencia accidental de secuencias heterogéneas de eventos físicos" (GkW 746, 643), de la que difícilmente cabía extraer placer alguno ( $G k W 20-1$ y 51, 13 y 39). A saber: el perspectivismo astronómico de la reforma copernicana, junto con su inquietante duda sobre si la conexión entre el observador y lo observado era meramente fáctica y contingente $(G k W 121-2,101)$, preparaba la inversión exacta del citado postulado, a saber: "que lo invisible acabase por tener el valor de aquello que, en la tradición metafísica, había parecido poseer lo visible: la marca distintiva de ser el acceso a la realidad" (GkW 747, 643). Asimismo, el contemplator caeli irá perdiendo sus cualidades estéticas, puesto que los afanes astronómicos empezarán a concentrarse en un oscuro gabinete, en el que el astrónomo postcopernicano pasará buena parte de sus horas absorbido en la interminable digresión de sus cálculos matemáticos, mientras fuera, en el exterior, se despliega la compleja maquinaria del cielo nocturno, que en el interior el astrónomo intenta desentrañar ( $G k W 66-76,52-60)$.

\section{El contemplator caeli pierde su posición: la caída}

La anécdota de la caída de Tales de Mileto representa para Blumenberg el caso paradigmático de pérdida de la posición de espectador del contemplator caeli. De esta anécdota se ha ocupado Blumenberg ampliamente. En ella se narra la caída de Tales de Mileto en un pozo mientras observaba las estrellas, provocando la risa de la criada tracia que lo acompañaba. No sólo se trataría aquí de la dicotomía -en perspectiva astronómica- entre el "ser a la mano" y el "ser a desmano", sino del "ser a los pies" y sus libres variaciones: "perder el suelo bajo los pies", "estar con los pies en la tierra", "tener algo entre los pies", etc. Es éste, a nuestro juicio, un existenciario desatendido como tal por Heidegger, y que Blumenberg ha mostrado con gran elocuencia en sus dos grandes trabajos sobre la historia de la recepción de la anécdota de Tales, Der Sturz des Protophilosophen [1976] y Das Lachen der Thrakerin [1987]. Citamos a continuación un pasaje del primero:

El último Heidegger no recuerda ya [...] el resultado elemental de la analítica de la existencia de Ser y tiempo, que se podría definir como la postrera radicalización de la primitiva experiencia filosófica, simbolizada en la anécdota de Tales: cierto es que para el filósofo de Mileto, lo más cercano, aquello que tenía delante de los pies, era tan lejano como para caer dentro, pero es precisamente el realismo de la caída, y la risa que ella provoca, la que esconde y silencia la existencia de algo más lejano que se muestra como lo más cercano, hasta el punto de hacerle caer en un pozo. Heidegger lo ha definido 
como el resultado de la estructura hermenéutica de su ontología temprana: "El ente, que nosotros somos en cada momento, es ontológicamente el más lejano" (SdP 63, 87).

Atrapado entre lo aparente indisponible y lo oculto disponible, cegado para lo más inmediato, el milesio se aventuró en la espesura de la noche creyendo alcanzables las cosas de alto rango $(S d P 60,82)$, con el propósito firme de examinar cada uno de los cuerpos celestes "en su universalidad, sin descender jamás a nada concreto de lo que le es cercano [...] ni discutir aquello que tiene entre los pies ["dicht vor seinen Füßen"]" (SdP 13, 8), a causa de lo cual hubo de caer en un pozo excavado delante suyo. De ahí, en la tradición platónica de la anécdota, la recriminación de la criada tracia: el milesio quería conocer las cosas del cielo, ignorando las que tenía "ante las narices y los pies" ["was ihm vor der Nase und den Füßen läge"] $(\operatorname{SdP} 11,5)$.

El estado de cosas "a los pies" $(S d P 46,60)$ permanece por completo fuera de la Sorge del astrónomo, que dirige su atención con insistencia creciente hacia aquello remoto y a desmano. Es precisamente esta inquietud astronómica la que resulta súbitamente interrumpida por "las tangibles realidades que se extienden a sus pies" $(S d P 18,17)$, que exigen imperiosamente su atención y que definen el contenido legítimo de la Sorge, según el parecer de la tracia. A sus ojos vigilantes, Tales de Mileto cae justamente debido a que al intentar "escrutar los fenómenos del cielo, se le oculta aquello que permanece cercano ante sus pies" (SdP 32-3, 39). La tracia se siente entonces autorizada a amonestar a su amo, esgrimiendo "la tangible y vinculante realidad de la vida práctica y cotidiana" (SdP 32-3, 39), haciéndole reparar en las nudas realidades de la tierra, ${ }^{9}$ en su evidente incapacidad para alcanzar las estrellas $(S d P 46-7,61)$ y en su inaceptable desinterés hacia lo próximo.

Tales de Mileto permanece ajeno a las cosas del mundo, que le resultan tan extrañas y distantes como a la criada tracia los cuerpos celestes $(S d P 17,14)$. El vivo interés del protofilósofo por las estrellas se muestra entonces, y a todas luces, incompatible con el interés por los bajos asuntos de la tierra, por ello "cae sobre el pensador la risa de la cotidianidad, absorbida en sus propios cuidados" (LdT 1545 , 201). La risa comporta "implicaciones no sólo para aquello que se cree permanece remoto al hombre, sino también para todo lo que propiamente le debería ser cercano" (SdP 45-6, 58-9). Lo uno es irrelevante y trivial, mientras que lo otro es necesario y va de suyo. Lo lejano e insignificante es, por supuesto, lo celeste indisponible, mientras que lo terrestre disponible es aquello verdaderamente importante,

\footnotetext{
${ }^{9}$ Reinhart Herzog ha llamado la atención sobre la circunstancia de que en la historia de la recepción de la anécdota de la caída de Tales no hay rastro de una ulterior réplica del protofilósofo a la criada tracia, "die Frage nach Thales's Antwort". Para más detalles sobre el "silencio de Tales" véase su magnífico "Das Schweigen des Thales", en Michael Krüger (ed.), Akzente. Hans Blumenberg zum 70. Geburtstag, 37 Jahrgang, Heft 3, Juni 1990, pp. 221-3.
} 
con lo que termina por tropezar el protofilósofo ( $L d T$ 112, 147; SdP 25, 27): "las tangibles realidades que están delante de los pies" (SdP 18-9, 17).

Tales de Mileto habría pasado por alto que "el terreno que pisa no es precisamente el de una estrella" (SdP 32-3, 39), por ello tuvo que acabar "en la suciedad de la tierra" (SdP 32-3,39), dado que su paseo astronómico nocturno, como su afán por lo inalcanzable $(S d P 60,84)$, era completamente inútil y contraproducente $(S d P 22,22)$. Semejantes inquietudes, no podían arrojar un resultado más aleccionador: perder el suelo bajo los pies: "el suelo bajo los pies es la metáfora más socorrida cuando hay que lamentar la pérdida de realidad y realismo; cuando hay que describir el abandono del mundo de la vida; el suelo bajo los pies se convierte en metáfora de las seguridades inadvertidas de las que se compone el síndrome de la mundaneidad vital" (LdT 116, 153).

\section{Imágenes y metáforas de la indisponibilidad}

Queremos concluir este artículo examinando brevemente algunas de las representaciones metafóricas del "ser a desmano" en tanto condición existencial, que Blumenberg ha ido consignando a lo largo de su historia de la astronomía, sobre todo en relación con lo que podemos denominar las "metáforas de la indisponibilidad".

Quizá la más emblemática de todas ellas corresponde a la conocida distinción aristotélica entre mundo sublunar y mundo supralunar, que para Blumenberg parece definir el caso paradigmático de resignación astronómica. Esta distinción de mundos no sólo tematiza la inadecuación entre el intelecto humano y el firmamento, sino que, tomada metafóricamente $(G k W 227,192)$, simboliza el abismo entre aquello próximo a la mano y aquello otro radicalmente desconocido e inalcanzable, que además no es susceptible de ser representado. El mundo supralunar establece la difusa esfera de lo indisponible, que escapa, en su distancia absoluta respecto al hombre, a cualquier intento de intervención o apropiación. Ni siquiera cabe aventurar sus rasgos más generales, debido a que "los atributos de los cuerpos celestes no pueden ser expresados en conceptos derivados de los cuerpos terrestres" (GkW $227,192)$. Por añadidura, y a la manera de la doctrina estoica cosmológica, el mundo supralunar se eleva como "el criterio más alto de la ambigüedad de los cielos" (GkW 28, 19), en la cifra perfecta del "escándalo de la fijación irrevocable del hombre a su situación en el mundo" $(G k W 28,19)$. Un mundo, además, desprovisto de providencia alguna $(S d P 29,34)$. La distinción aristotélica, tomada como metáfora de la indisponibilidad, señala la brecha existente entre la realidad que sustenta al hombre, ya desde siempre traicionado y atrapado en "la trampa de la inmediatez" ( $S d P 12,7)$, y la realidad inasequible del orden numinoso eternamente ajeno. 
Podemos asociar a esta peculiar metáfora de la indisponibilidad, que estaríamos tentados a calificar como absoluta, la tradición de metáforas cosmológicas mayestáticas ( $G k W 731-2,629-30)$, de acuerdo con las cuales una porción incierta del firmamento corresponde al "espacio inaccesible reservado a Dios" (GkW 731-2, 62930). Estas metáforas, de claro contenido existencial, se orientan prevalentemente a mostrar "que no todo en el mundo concierne al hombre" (GkW 731-2, 630), y de manera especial, aquello que está sustentado sobre su cabeza, merecedor, no obstante, de ser considerado con admiración, respeto y reverencia.

Sin embargo pocas metáforas han sido tan recurrentes en la historia blumenberguiana de la astronomía como la del pozo. El pozo ofrece una de las imágenes más pregnantes de la indisponibilidad, bien porque representa a una verdad atrapada en su fondo, como en Demócrito o Lactancio (PM 50-4, 92-6; LdT 97, 127), o bien porque se puede caer en él, como en la anécdota de Tales $(S d P ; L d T)$ o como en los cuentos del barón Münchhausen $(G k W 199,168)$, quien decía ser capaz de salir de ellos estirándose de sus cabellos.

No vamos a insistir en esta metafórica porque nos hemos ocupado de ella en otro lugar. ${ }^{10}$ Preferimos hacer referencia a la ambivalente metáfora del carruaje en Kierkegaard. Blumenberg la ubica en la tradición de las "metáforas de la luz" ( $G k W$ $138,114)$, con la particularidad de que especificaría el caso de quien, ante un exceso de luz que le ciega, trata de oscurecer su situación para poder ver mejor: "probablemente fue Kierkegaard el primero que encontró una imagen para esta forma de auto-oscurecimiento por medio de la propia luz" (GkW 138, 114). En 1845 Kierkegaard anota en su diario la escena de un hombre rico que conduce en la densa oscuridad de la noche guiado por las luces de su carruaje, de tal modo que puede ver un área extremadamente pequeña mucho mejor que el hombre pobre que, debido a que conduce sin luces, nada ve delante suyo, pero sí puede contemplar, en cambio, la vasta panorámica del firmamento. El hombre rico se orienta en lo más inmediato a condición de prescindir de la percepción de lo lejano, aquello que contempla a voluntad el temerario hombre pobre, pero a condición, a su vez, del riesgo de no ver lo cercano: "el 'hombre rico' no es una categoría social sino religiosa; es la persona que confía en sus medios, en el realismo de lo más cercano ["Realismus des Nächstliegenden"], cuya luz es incuestionablemente la de la racionalidad: ello le permite ver mejor, pero las estrellas se le ocultan" (GkW 138,114). Kierkegaard no podía anticipar, a diferencia de Simmel $(H 76,69)$, que las luces de la ciudad llegasen a convertir la noche en día, ocultando el paisaje y el cielo estrellado. Las ciudades modernas, sumidas en su luz efervescente, impiden dirigir la mirada hacia lo alto, hacia aquello "inaccesible, insustituible y no manipulable, esto es, aquello que se establece como el valor límite de cada cultura en relación con lo cual el 'aura práctica' se desvanece" $(G k W 138,114)$.

10 Alberto Fragio, "Hans Blumenberg e la storia dell'arte moderna. Una comprensione fauve della metaforologia", Calixtilia, n. I, Lampi di stampa, Milano, 2010, pp. 53-76. 
Una situación del género, era también la del astrónomo Tycho Brahe, que "se creía capaz de encontrar el camino más corto para su carruaje guiándose por las estrellas" (LdT 109, 143). Pero su cochero, a la manera del hombre rico de Kierkegaard y de la criada tracia de Tales, no pudo sino replicarle: "Señor, posiblemente se entienda bien en el cielo, pero aqui sobre la tierra es usted un loco" (LdT $109,143)$. Semejante respuesta no es tanto una censura, sostiene Blumenberg, como "un dictamen sobre un conflicto de competencias" (LdT 109, 143), emitido por quien se sabe autorizado respecto a la disposición pragmática de los asuntos mundanos. El simultáneo reconocimiento y desautorización por parte del cochero reside, a nuestro modo de ver, en la maniobra ilegítima y perversa de intentar hacer disponible lo terrestre mediante la observación de lo celeste. El conocimiento de la posición y cinemática de las estrellas se sanciona entonces como un saber inútil y contraproducente si de lo que se trata es de encontrar el camino más corto en la superficie de la Tierra.

Pero la imagen más deliciosa de esta metafórica del carruaje, la ofrece sin duda la anécdota de Voltaire y Madame du Châtelet. Durante un viaje a Cirey, en 1747, la carroza de Voltaire se rompe, arrojando fuera a sus ocupantes. El secretario que los acompañaba fue enviado al pueblo más cercano a pedir auxilio, y a su vuelta "vió una escena llena de ridícula falta de realismo y desprecio hacia las duras realidades terrenas" (SdP 40,51). Voltaire y Mme. du Châtelet estaban sentados uno junto al otro sobre el acolchado de la carroza accidentada, que habían extraído y dispuesto sobre la nieve, de tal forma que sentados sobre ese relleno observaban la belleza del cielo estrellado: "capturados por la grandeza del espectáculo que se extendía en derredor, conversaban, temblando de frio, a pesar de las pieles que los envolvían, sobre la naturaleza y las órbitas descritas por las estrellas, sobre el destino de los innumerables cuerpos celestes en el espacio infinito" (SdP 40,51). Para su completa felicidad sólo habrían precisado, según el testimonio del secretario, de los instrumentos ópticos oportunos con los que escrutar la profundidad de los cielos, "sin darse cuenta de su triste situación en la Tierra" $(S d P 40,51)$. La llegada del auxilio no podía sino interrumpir la gozosa "contemplación cósmica y el coloquio sobre el universo" (SdP 40, 51).

De entre las otras muchas metafóricas de la indisponibilidad que cabrían aducirse, como la metáfora orgánica del Idealismo $(G k W 81-2,66-7)$, la de la torre de Babel $(G k W 96,78)$ o la metaforización de la invisibilidad $(G k W 125,103)$, queremos hacer referencia sólo, y sin ánimo exhaustivo, a la ambigua metáfora de "la completa contabilidad de las estrellas" ["Die Vollzähligkeit der Sterne"] (VS 16), que quizá cabría asignar, propiamente, a las metáforas existenciales de la disponibilidad. Nos referimos al poema "El pozo viejo" ["Der alte Brunnen"] de Hans Carossa, que Blumenberg califica de "canción noctura" ["Nachtlied"] (VS 13), esto es, de nana. En dicho poema Carossa describe la escena de un huésped alojado por 
vez primera en una modesta casa de campo, cercana a un pozo solitario que hace también las veces de fuente: "debe primero acostumbrarse a su suave murmullo, pero se acostumbra tanto que se despierta cuando el sonido se interrumpe" ["wenn der Ton aussetzt"] (VS 13). El dueño de la casa debe entonces tranquilizarlo: "un caminante nocturno ha interrumpido el chorro con su mano vacía para tratar de beber" (VS 13). Es ésta, dice Blumenberg, "una experiencia en la soledad, que no es definitiva" ["Erfahrung in der Einsamkeit, daß sie nicht endültig ist"] (VS 13). Aún habrán de venir más caminantes nocturnos a beber, señalando su paso con el breve y ocasional silencio del rumor de la fuente, para luego proseguir de nuevo su camino (VS 13). En elaboraciones sucesivas del poema, el sobresaltado durmiente habría de encontrar consuelo, no tanto en las confiadas palabras del posadero, como en la "completa contabilidad" ["vollzählbar"] (VS 16) de las estrellas que componen el firmamento, que el durmiente encuentra ahí mismo nada más despertar. Si bien la fuente puede ser perturbada, y con ello el sueño reparador, no así el orden del mundo, simbolizado en la inequívoca estabilidad del cielo estrellado. Pero no se trata sólo de que el cielo en sí mismo permanezca invariable y sirva como referente para quien resurge desorientado en el mundo tras la interrupción abrupta de su descanso. Más bien, lo que está en juego es la posibilidad de poder contar las estrellas que pueblan el firmamento, y con ello, volver a conciliar el sueño: "no es importante que el recuento se produzca efectivamente, sino que se pueda hacer" (VS 16).

Hemos sacado a colación, y para terminar, esta configuración simbólica en tanto metáfora de la indisponibilidad, porque en su ambigua formulación se especifica también el carácter inalcanzable del universo. Como en la canción popular que inspiraba el poema de Carossa, pronto se impone la duda ":Sabes cuántas estrellas van?" ["Weißt du wieviel Sternlein gehen?"] (VS 17). Debido a que la tarea efectiva de contarlas hasta el final es de hecho inasumible, se ha de insistir en la mera posibilidad de su recuento. Así lo pone también de relieve el persistente fracaso de las catalogaciones o cartografías estelares, una empresa cuyo cumplimiento siempre ha de ser pospuesto para las generaciones futuras ( $L W$ 99-152, 89-134; VS 79101): el cielo estrellado permanece tan alejado e indisponible como siempre, por más que su brillante y contable apariencia nos ayude a conciliar el sueño mientras yacemos en una Tierra excéntrica que recorre impasible su órbita vacía.

\section{Índice de siglas y referencias bibliográficas}

\section{Obras de Hans Blumenberg}

(AM) Arbeit am Mythos [1979], Frankfurt am Main, Suhrkamp, 2006. Trad. esp. Pedro Madrigal, Trabajo sobre el mito, Barcelona, Editorial Paidós, 2003. 
(BiG) Begriffe in Geschichten, Frankfurt am Main, Suhrkamp, 1998. Trad esp. César G. Cantón y Daniel Innerarity, Conceptos en historias, Madrid, Editorial Síntesis, 2003.

(BdM) Beschreibung des Menschen. Frankfurt am Main, Suhrkamp, 2006.

(CC) "Contemplator Caeli", en Dietrich Gerhardt, Wiktor Weintraub y Hans-Jürgen zum Winkel (eds.), Orbis Scriptus. Festschrift für Dmitrij Tschizewskij zum 70. Geburtstag, München, Fink, 1966, pp. 113-24.

(dem) "Pierre Lecomte du Noüy: Die Entwicklung zum Menschen als gelstig-sittlichem Wesen", en Deutsche Universitätszeitung, 9, 21, 1954, p. 19.

(dS) Die Sorge geht über den Fluß, Frankfurt am Main, Suhrkamp, 1987. Trad. esp. Jorge Vigil y Manuel García Serrano, La inquietud que atraviesa el río. Ensayo sobre la metáfora [1987], Ediciones Península, Barcelona, 1992.

(EmS) Ein mögliches Selbstverständnis. Aus dem Nachlaß, Stuttgart, Reclam, 1997. Trad. esp. César González Cantón y Daniel Innerarity, La posibilidad de comprenderse, Madrid, Síntesis, 2002.

(H) Höhlenausgänge [1989], Frankfurt am Main, Suhrkamp, 1996. Trad. esp. José Luis Arántegui, Salidas de la caverna, Madrid, Antonio Machado Libros, 2004. ( $L d N)$ Die Legitimität der Neuzeit, [1966], Frankfurt am Main, Suhrkamp, 1996. Trad. fran. Marc Sagnol, Jean-Louis Schlegel, Denis Trierweiler y Marianne Dautrey, La légitimité des Temps modernes, Paris, Gallimard, 1999.

(LdT) Das Lachen der Thrakerin. Eine Urgeschichte der Theorie, Frankfurt am Main, Suhrkamp, 1987. Trad. esp. Isidoro Reguera, La risa de la muchacha tracia. Una protohistoria de la teoría, Valencia, Pre-textos, 2000.

(Leg) Die Lesbarkeit der Welt, Frankfurt am Main, Suhrkamp, 1981. Trad. esp. Pedro Madrigal, La legibilidad del mundo, Barcelona, Editorial Paidós, 2000.

$(G k W)$ Die Genesis der kopernikanischen Welt [1975] Frankfurt am Main, Suhrkamp, 2007. Trad. ingl. Robert M. Wallace, The Genesis of the Copernican World, Cambridge, MIT Press, 1987.

$(s W)$ "Die sprachliche Wirklichkeit der Philosophie", Hamburger Akademische Rundschau 1, 10, 1946/7, pp. 428-31.

( $L a M)$ "Licht als Metapher der Wahrheit. Im Vorfeld der philosophischen Begriffsbildung", Studium Generale 10, 7, 1957, pp. 432-47.

(Löw) Löwen, Frankfurt am Main, Suhrkamp, 2001.

(Lt) Lebensthemen. Aus dem Nachlaß, Stuttgart, Reclam, 1998.

(LT) "Lebenswelt und Technisierung unter Aspekten der Phänomenologie" en Wirklichkeiten in denen wir leben. Aufsätze und eine Rede. Stuttgart, Reclam, 1981, pp. 7-54. Trad. esp. Pedro Madrigal "'Mundo de la vida” y tecnificación bajo los aspectos de la fenomenología", en Realidades en las que vivimos, Barcelona Paidós ICE/UAB, 1999, pp. 33-73. 
(LW) Lebenszeit und Weltzeit [1986], Frankfurt am Main, Suhrkamp, 2001. Trad. esp. Manuel Canet, Tiempo de la vida y tiempo del mundo [1986], Valencia, Pretextos, 2007.

(Mp) Matthäuspassion, Frankfurt am Main, Suhrkamp, 1988.

(Nruf) "Nachruf auf Erich Rothacker. Gehalten am 29. April 1966 in der Offentlichen Sitzung der Akademie der Wissenschaften und der Literatur", Jahrbuch der Akademie der Wissenschaften und der Literatur in Mainz, 1966, pp. 70-6.

(PM) Paradigmen zu einer Metaphorologie [1960], Frankfurt am Main, Suhrkamp, 1998. Trad. esp. de Jorge Pérez de Tudela Velasco, Paradigmas para una metaforología, Madrid, Trotta, 2003.

$(S d P)$ "Der Sturz des Protophilosophen. Zur Komik der reinen Theorie - anhand einer Rezeptionsgeschichte der Thales-Anekdote", en Wolfgang Preisendanz, Rainer Warming (eds): Das Komische, München, Fink, 1976, pp. 11-64.

(SZ) Schiffbruch mit Zuschauer. Paradigma einer Daseinsmetapher [1979], Frankfurt am Main, Suhrkamp, 1988. Trad. esp. Jorge Vigil, “Aproximación a una teoría de la inconceptualidad" en Hans Blumenberg, Naufragio con espectador. Paradigma de una metáfora de la existencia [1979], Madrid, Visor, 1995. (VPh) Die Verführbarkeit des Philosophen [2000], Frankfurt am Main, Suhrkamp, 2005.

(VS) Die Vollzähligkeit der Sterne [1997], Frankfurt am Main, Suhrkamp, 2000.

$(W b M)$ "Wirklichkeitsbegriff und Möglichkeit des Romans", en Hans Robert Jauss (ed.): Nachahmung und Illusion, München, Fink, 1964, pp. 9-27.

(ZdS) Zu den Sachen und zurück [2002], Frankfurt am Main, Suhrkamp, 2007.

\section{Obras sobre Hans Blumenberg}

Behrenberg, P.: Endliche Unsterblichkeit. Studien zur Theologiekritik Hans Blumenbergs, Würzburg, Königshausen y Neumann, 1994.

Borsari, A. (ed.): "Hans Blumenberg", en Hans Blumenberg. Mito, metafora, modernità, Bologna, il Mulino, 1999.

Fragio, A.: "Wittgenstein según Blumenberg", Logos. Anales del seminario de metafísica, vol. 42, 2009, Universidad Complutense de Madrid, pp. 261-86.

Fragio, A.: "Hans Blumenberg e la storia dell'arte moderna. Una comprensione fauve della metaforologia", Calixtilia, n. I, Lampi di stampa, Milano, 2010, pp. 53-76.

Fragio, A.: "La ontología cosmológica en la obra temprana de Hans Blumenberg: las Beiträge y Die ontologische Distanz", Res publica, vol. 23, Murcia, 2010, pp. 93-122. 
Fragio, A.: "Das Überleben der Übergänge: nuevos paradigmas de análisis de la obra de Hans Blumenberg", en Fragio, A. y Giordano, D. (eds.): Hans Blumenberg. Nuovi paradigmi d'analisi, Roma, Aracne Editrice, 2010.

GonZÁlez CANTÓN, C.: La metaforología de Blumenberg como destino de la analítica existencial, Universidad Complutense de Madrid, 2004.

Haverkamp, A. y Mende, D. (eds.): Metaphorologie. Zur Praxis von Theorie, Frankfurt am Main, Suhrkamp Verlag, 2009.

HeIDENReich, F.: Mensch und Moderne bei Hans Blumenberg, München, Wilhelm Fink Verlag, 2005

Hundeck, M., Welt und Zeit. Hans Blumenbergs Philosophie zwischen Schöpfungsund Erlösungslehre, Würzburg, Echter, 1999.

Monod, J.C.: Hans Blumenberg, Paris, Belin, 2007.

Müller, O.: Sorge um die Vernunft. Hans Blumenbergs phänomenologische Anthropologie, Paderborn, Mentis Verlag, 2005.

Pavesich, V.: Hans Blumenberg: An Anthropological Key, University of California at San Diego, 2003.

Stoellger, P.: Metapher und Lebenswelt: Hans Blumenbergs Metaphorologie als Lebenswelthermeneutik und ihr religionsphänomenologischer Horizont, Tübingen, Mohr Siebeck, 2000.

VillacaÑas, J. L.: "De nobis ipsis silemus. Reflexiones sobre Hans Blumenberg, lector de Kant", $H M i C$, Universidad Autónoma de Barcelona, 2004.

WeTz, F.-J.: Hans Blumenberg zur Einführung, Hamburg, Junius Verlag GmbH, 2004.

Alberto Fragio

Eidgenössische Technische Hochschule Zürich

Chair for Science Studies

albfragio@gmail.com 